\title{
BMJ Open Modelling the lifetime cost- effectiveness of catheter ablation for atrial fibrillation with heart failure
}

\author{
Lan Gao, ${ }^{\circledR}$ Marj Moodie
}

To cite: Gao L, Moodie M. Modelling the lifetime costeffectiveness of catheter ablation for atrial fibrillation with heart failure. BMJ Open 2019;9:e031033. doi:10.1136/ bmjopen-2019-031033

- Prepublication history and additional material for this paper are available online. To view these files, please visit the journal online (http://dx.doi. org/10.1136/bmjopen-2019031033).

Received 12 April 2019 Revised 01 July 2019 Accepted 12 July 2019

Check for updates

(C) Author(s) (or their employer(s)) 2019. Re-use permitted under CC BY-NC. No commercial re-use. See rights and permissions. Published by BMJ.

Deakin University, Faculty of Health, Institute for Health Transformation, Deakin Health Economics, Geelong, Victoria, Australia

Correspondence to

Dr Lan Gao;

lan.gao@deakin.edu.au

\section{ABSTRACT}

Objectives Assessing the cost-effectiveness credentials of this intervention in patients with concomitant atrial fibrillation (AF) and heart failure (HF) compared with usual medical therapy.

Design A Markov model comprising two health states (ie, alive or dead) was constructed. The transition probabilities were directly derived from published Kaplan-Meier curves of the pivotal randomised controlled trial and extrapolated over the cohort's lifetime using recommended methods. Costs of catheter ablation, outpatient consultations, hospitalisation, medications and examinations were included. Resource use and unit costs were sourced from government websites or published literature. A lifetime horizon and a healthcare system perspective were taken. All costs and benefits were discounted at 3\% annually. Deterministic (DSA) and probabilistic sensitivity analyses (PSA) were run around the key model parameters to test the robustness of the base case results.

Participants A hypothetical Australian cohort of patients with concomitant $\mathrm{AF}$ and HF who are resistant to antiarrhythmic treatment.

Interventions Catheter ablation versus medical therapy. Results The catheter ablation was associated with a cost of \$A44 377 per person, in comparison to \$A28 506 for the medical therapy alone over a lifetime. Catheter ablation contributed to 4.58 quality-adjusted life years (QALYs) and 6.99 LY gains compared with 4.30 QALYs and 6.53 $\mathrm{LY}$ gains, respectively, in the medical therapy arm. The incremental cost-effectiveness ratio was \$A55 942/QALY or $\$ A 35$ 020/LY. The DSA showed that results were highly sensitive to costs of ablation and time horizon. The PSA yielded very consistent results with the base case. Conclusions Offering catheter ablation procedure to patients with systematic paroxysmal or persistent AF who failed to respond to antiarrhythmic drugs was associated with higher costs, greater benefits. When compared with medical therapy alone, this intervention is not costeffective from an Australia healthcare system perspective.

\section{INTRODUCTION}

Chronic heart failure (HF) and atrial fibrillation (AF) are common conditions that contribute significantly to the risk of death worldwide. Both conditions are becoming increasingly prevalent and resulting in spiralling costs to healthcare systems internationally. ${ }^{1-3}$ The incidence of AF is predicted to

\section{Strengths and limitations of this study}

This is the first study that used the evidence from recently published randomised controlled trial (RCT) to assess the cost-effectiveness of catheter ablation in treating patients concomitant with atrial fibrillation and heart failure.

- The reconstructed individual patient data (IPD) was derived from published Kaplan-Meier curve from the $\mathrm{RCT}$, which were used to derive the transition probabilities in the Markov model.

- Extensive sensitivity analyses were undertaken to test the robustness of the results, including consideration of different parametric survival models to extrapolate the survival observed over the trial.

- The reconstruction of the IPD is only a maximum approximation of the real data, but the algorithm used to derive the IPD is considered reliable.

double over the next 20 years. ${ }^{45} \mathrm{HF}$ is the leading cause of hospitalisation among adults aged over 65 years of age with more than 41 000 people hospitalised annually in Australia. ${ }^{6}$ Despite dramatic improvement in outcomes in patients treated with medical therapy, more than $50 \%$ of patients with HF are rehospitalised within 6 months of discharge ${ }^{7}$ and around $40 \%$ of them are diagnosed with $\mathrm{AF}$ within 12 months. ${ }^{8}$ Rates of HF were $33 \%$ in paroxysmal, $44 \%$ in persistent and $56 \%$ in permanent AF. ${ }^{9}$ Therefore, the combination of these two conditions has a dramatic impact on healthcare and warrants consideration of new models of care.

$\mathrm{HF}$ and $\mathrm{AF}$ are closely correlated in terms of pathophysiology and risk factors. ${ }^{9} 10$ Owing to the complex interaction resulting in the impaired systolic and diastolic function absent in sinus rhythm, AF can be a cause or an outcome of HF. ${ }^{11} \mathrm{AF}$ is associated with significantly increased risk (ie, three times) of de novo HF. ${ }^{11}$ On the contrary, development and progression of $\mathrm{AF}$ are much more likely to ensue in the presence of structural and neurohormonal variations seen in $\mathrm{HF}^{12}$ Moreover, patients with comorbid $\mathrm{HF}$ and $\mathrm{AF}$ 
have significantly poorer prognosis irrespective of which onsets first. ${ }^{13}{ }^{14}$ In view of the poor clinical outcome relating to these two conditions, it is always critical and challenging to discover the most effective treatment, for example, treatments effectiveness shown in one condition or the other independently can be inconsistent with that revealed in the combined conditions and even raise safety issues. ${ }^{1516}$ This is the case for catheter ablation.

Catheter ablation is a well-established option for symptomatic AF that is resistant to drug therapy in patients with otherwise normal cardiac function. ${ }^{17-19}$ Lack of both clinical evidence and consensus from guidelines ${ }^{2021}$ regarding the best management approach for patients with $\mathrm{HF}$ and AF concomitantly leaves a huge knowledge gap in this field. Very recently, the effectiveness of catheter ablation in improving hard primary endpoints such as death or the progression of $\mathrm{HF}$ in patients comorbid with $\mathrm{HF}$ was tested in a large, randomised controlled trial. ${ }^{22}$ The study showed that, after a median follow-up of 37.8 months, the primary composite end point consisting of death from any cause or worsening of HF that led to an unplanned hospitalisation, occurred in significantly fewer patients in the ablation group than the medical therapy group (HR $0.62,95 \%$ CI 0.43 to $0.87, \mathrm{p}=0.007$ ). ${ }^{22}$

The unanswered question now is whether it is cost-effective to offer catheter ablation to patients comorbid with $\mathrm{HF}$ and AF given (1) the cost-effectiveness credential for catheter ablation in AF is not directly applicable to a patient group with concomitant HF and AF; (2) scarce healthcare resources.

The primary aim of this study was to assess the lifetime cost-effectiveness of catheter ablation compared with conservative medical therapy in treatment patients with concomitant AF and HF from an Australian healthcare system perspective.

\section{METHODS}

A modelled economic evaluation was performed to assess the cost-effectiveness of catheter ablation in treating Australian patients with concomitant $\mathrm{AF}$ and $\mathrm{HF}$ from a healthcare system perspective over a lifetime horizon. More specifically, the patients modelled had a median age of 64 years, were predominantly male (over $84 \%$ ), failed to respond/contraindicated to antiarrhythmic medications and had one of three types of AF (ie, paroxysmal, persistent, long-standing persistent). A majority (over $58 \%$ ) of the modelled population had class II heart function as rated by the New York Heart Association. ${ }^{22}$

\section{Model structure}

A Markov model was developed to estimate the costs and health outcomes associated with catheter ablation and medical therapy for a hypothetical cohort of Australian patients. The model took a lifetime horizon and the economic perspective of the model was the Australian healthcare system. Two health states were considered (1) alive or (2) dead. The Markov model used a monthly cycle length with half-cycle correction and assigned each patient a monthly probability of death based on the time elapsed and type of treatment received. In each cycle, the patients who were alive were exposed to the risk of rehospitalisation due to worsening of $\mathrm{HF}$ (readmission to a hospital for HF-related complications or other causes). Each patient then accrued lifetime healthcare costs including treatment (catheter ablation, medications), outpatient care and examinations, quality-adjusted life years (QALYs) and life years (LYs) according to their hospitalisation and treatment status. The model structure is shown in figure 1. The Markov model was built using TreeAge (TreeAge Pro 2017, R2.1. TreeAge Software, Williamstown, Massachusetts, USA).

\section{Model inputs}

\section{Transition probabilities}

The clinical effectiveness of catheter ablation was derived from the key clinical study. ${ }^{22}$ Since the median follow-up was only 37.8 months, the outcome observed during the trial was extrapolated beyond the duration of the trial follow-up. Specifically, the method described by Guyot et $a l^{23}$ was adopted to derive the individual patient data (IPD) base on published Kaplan-Meier curves (a validated graphical digitiser, WebPlotDigitizer V3.9 (http:// arohatgi.info/WebPlotDigitizer), was used to extract the graphic data). Parametric survival curves, including exponential, Weibull, log-logistic, log-normal, gompertz and generalised gamma distributions were fitted to the reconstructed IPD to extrapolate to a longer time horizon ('flexsurv' package of $\mathrm{R}$ ). The process of fitting parametric survival curves to IPD was based on guidance provided by the Decision Support Unit at the National Institute for Health and Care Excellence (NICE).$^{24}{ }^{25}$ In brief,

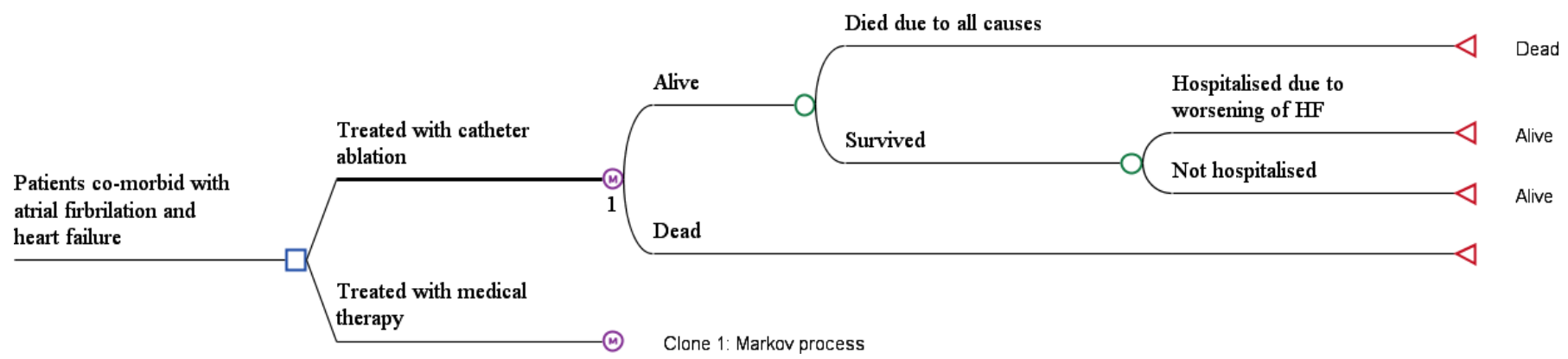

Figure 1 Markov model used for the economic evaluation. 
this entailed (1) testing of proportional effects assumption (ie, the log cumulative hazard) to determine if the survival curves of catheter ablation and medical therapy groups were parallel; (2) then fitting the reconstructed IPD with single or separate distribution(s) depending on the conclusion of the first step and (3) determining of the most appropriate fit by both visual inspection and Akaike Information Criterion (AIC) and Bayesian Information Criterion (BIC) goodness-of-fit statistics. If the fitted curves were similar by distributions (ie, Weibull, exponential and so on) tested in terms of visual inspection, the most appropriate model was selected based on the lowest AIC and BIC values. The Kaplan-Meier curves built on reconstructed IPD are presented in the online supplementary figures 1 and 2 . As the proportional hazard assumption did not hold for the overall survival and time to event (ie, hospitalisation for worsening HF) curves, independent parametric curves were fitted separately for two treatment groups (log cumulative hazard and cumulative hazard for two arms are shown in the online supplementary figures 3 to 4 ). Based on the criteria set above, log-normal distribution was selected for the time to hospitalisation (see online supplementary figures 5 to 6 ) of both catheter ablation and medical therapy arms, while Weibull and exponential distributions were chosen to extrapolate the overall survival data for medical therapy and catheter ablation groups, respectively (see online supplementary figures 7 to 8 ). Parameters of the each of the distributions used to parameterise the fitted curves are shown in the online supplementary tables 1 and 2 .

The time-dependent transition probabilities from alive to death and from alive to hospitalisation for the first 48 months of the time horizon were directly read from the published Kaplan-Meier curves. ${ }^{26}$ From that time-point beyond, time-dependent transition probabilities were calculated from the extrapolated curves as described above. Since the literature indicated that the effectiveness of AF catheter ablation is likely to be sustained for $3-5$ years, ${ }^{27}$ the aforementioned transition probabilities for the catheter ablation group were assumed to be the same as the medical therapy group after 3 years. All the transition probabilities are presented in the online supplementary table 3 .

\section{Costs}

All costs and resource use inputs were obtained from publicly available sources. The costs taken into account included: catheter ablation (including hospitalisation to perform the procedure), medication, examination, hospitalisation due to worsening of $\mathrm{HR}$, cost related to death event and adverse events (AEs) related to the catheter ablation procedure. All the costs and resource uses are presented in tables 1 and 2 and online supplementary table 4 .

\section{Utilities}

The baseline utility for patients with HF and the disutility caused by hospital readmission for HF were incorporated into the model. The disutility associated with hospitalisation and/or AEs due to undergoing a catheter ablation procedure was assumed to be same as the disutility of a hospital admission for HF and was assumed to be sustained for 1 year. The sources and utility/disutility values populated in the model are shown in online supplementary table 5 .

Model assumptions, time horizon, cycle length and perspective Australian patients who were unresponsive to antiarrhythmic medications and diagnosed with both $\mathrm{AF}$ and HF were simulated in the Markov model. The age of the population was defined as consistent with those recruited in the pivotal trial. A key assumption of the model was that the effectiveness of catheter ablation would be maintained to 5 years given the median follow-up of the trial was 37.6 months. The base case time horizon was set to 30 years to capture the lifetime treatment benefit from catheter ablation. However, varied time horizons were examined in the sensitivity analysis. As Australia has universal coverage of publicly funded health insurance (ie, Medicare), a healthcare system perspective was adopted to gauge the cost associated with catheter ablation in patients with $\mathrm{AF}$ and $\mathrm{HF}$; a 3\% discount rate was applied for costs, quality-adjusted life years (QALYs) and life years (LYs). A monthly cycle length with half-cycle correction was employed to model the risk of events patients may experience in the long-term.

\section{Cost utility analyses}

Incremental cost-effectiveness ratios (ICERs) were calculated on the basis of two outcomes: QALY and LY gained. The commonly quoted willingness to pay (WTP) per QALY threshold of \$A50 000 in Australia ${ }^{28}$ was adopted to assess whether the catheter ablation was cost-effective. A cost-effectiveness acceptability curve was constructed to examine the probability of the intervention being cost-effective under various WTP/QALY thresholds.

\section{Sensitivity analyses}

A series of one-way deterministic sensitivity analyses were conducted to test the robustness of base case results. Where applicable, the key model parameters (ie, discount rate, time horizon, cost of catheter ablation, etc) were varied within a plausible range informed by literature or assumptions (see online supplementary table 6 ). The results from the one-way sensitivity analyses are shown in terms of Tornado diagrams, which sequentially graph the variables with the largest impact on the cost-utility results. Probabilistic sensitivity analyses (PSA) were performed to assess the overall impact of uncertainty in the model by defining distributions for the key parameters (ie, variables regarding utility and costs) (table 3). Five thousand iterations were run to construct a mean and $95 \%$ CI for the corresponding costs, and benefits and the results were plotted on the cost-effectiveness plane.

\section{Patient and public involvement}

No patients or public were involved in the study. 
Table 1 Unit cost of resource use items

\begin{tabular}{|c|c|c|c|c|}
\hline Resource uses & $\begin{array}{l}\% \text { of Patients } \\
\text { using this } \\
\text { resource }\end{array}$ & Source & Unit cost & Sources of unit cost \\
\hline \multicolumn{5}{|l|}{ Medications* } \\
\hline Antiarrythmic agents & 43.5 & Roy et al $2008^{39}$ & $\$ A 24.01$ & $\begin{array}{l}\text { PBS 2923W, 2876J, 1088G, 2343H, 2344J, } \\
\text { 2043M, 8396B }\end{array}$ \\
\hline$\beta$-blockers & 79 & Roy et al $2008^{39}$ & $\$ A 30.90$ & $\begin{array}{l}\text { PBS 2961W, 3062E, 2565B, 2566B, 2566C, } \\
\text { 1081X, 2243C, 8640W, 8605X, 8606Y, 6732N, } \\
\text { 8733P, 8743Q, 8735R, 1324Q, 1325R, 9311C, } \\
\text { 9312D, 9316H }\end{array}$ \\
\hline Long-acting nitrates & 17 & Roy et al $2008^{39}$ & $\$ A 24.39$ & $\begin{array}{l}\text { PBS } 11 \text { 027J, } 11 \text { 051P, 1459T, 1515R, 1516T, } \\
3475 \mathrm{X}, 5108 \mathrm{~W}, 8010 \mathrm{~N}, 8011 \mathrm{P}, 8026 \mathrm{~K}, 8027 \mathrm{~L} \text {, } \\
8028 \mathrm{M}, 8119 \mathrm{H}, 8171 \mathrm{C}, 2588 \mathrm{~F}, 1558 \mathrm{~B}, 8273 \mathrm{~K}\end{array}$ \\
\hline Calcium channel blockers & 2.5 & Roy et al $2008^{39}$ & $\$ A 16.19$ & $\begin{array}{l}\text { PBS 2751T, 2752W, 2361G, 2366M, 2367N, } \\
\text { 8534E, 8679T, 1694E, 1695F, 1906H, 1907J, } \\
\text { 8610E, 1241H, 1248Q, 1250T, 2208F }\end{array}$ \\
\hline Digoxin & 64.5 & Roy et al $2008^{39}$ & $\$ A 23.56$ & PBS 1322N, 2605D, 3164M \\
\hline ACE-I & 86 & Roy et al $2008^{39}$ & $\$ A 17.43$ & $\begin{array}{l}\text { PBS 1147J, 1148K, 1149 L, 8760C, 1368B, } \\
\text { 1369B, 1370D, 1182F, 1183G, 2456G, 2457H, } \\
\text { 2458J, 3050M, 3051N,8704D, 9006B, 9007C, } \\
\text { 9008D, 1968N, 1969P, 1316G, 1944H, 1945J, } \\
\text { 1946K, 8470T, 9120B, 9122D, 2791X, 2793B, } \\
8758 \mathrm{Y}\end{array}$ \\
\hline ARB & 11 & Roy et al $2008^{39}$ & $\$ A 19.39$ & $\begin{array}{l}\text { PBS 8295N, 8296P, 8297Q, 8889W, 5491B, } \\
\text { 8397Y, 8447N, 8951D, 8246B, 8247C, 8248D, } \\
\text { 5452Y, 8203R, 2147B, 2148C, 8355R, 8356T, } \\
\text { 9368C, 9369D, 9370E, 9371F }\end{array}$ \\
\hline Diuretics & 44.5 & Roy et al $2008^{39}$ & $\$ A 36.36$ & $\begin{array}{l}\text { PBS 1484D, 1585K, 2436F, 8532C, 1810G, } \\
\text { 1810G, 2411X, 2412Y, 2413B, 2414C, 2415D, } \\
\text { 3466K, 8879H, 8880J, 2339D, 2340E }\end{array}$ \\
\hline Antiplatelet agents & 38.5 & Roy et al $2008^{39}$ & $\$ A 15.46$ & $\begin{array}{l}\text { PBS } 4077 \mathrm{~N}, 10 \text { 169F, 2275R, 4179Y, 5436D, } \\
8358 \mathrm{X}, 9317 \mathrm{~J}, 9354 \mathrm{H}\end{array}$ \\
\hline Oral anticoagulants $\dagger$ & 88 & Roy et al $2008^{39}$ & $\$ A 69.74$ & PBS 5054B \\
\hline Lipid-lowering drug† & 43 & Roy et al $2008^{39}$ & $\$ A 69.72$ & PBS 10377E \\
\hline \multicolumn{5}{|c|}{ Outpatient care and examinations } \\
\hline Rehabilitation & 13.3 & $\begin{array}{l}\text { Neumanm et al } \\
2015^{40}\end{array}$ & $\$ A 62.25$ & MBS 10960 \\
\hline Emergency visitł & 1.2 & $\begin{array}{l}\text { Neumanm et al } \\
2015^{40}\end{array}$ & $\$ A 1985.00$ & AR-DRG F62C \\
\hline GP visits & 22.3 & $\begin{array}{l}\text { Neumanm et al } \\
2015^{40}\end{array}$ & $\$ A 37.05$ & MBS 23 \\
\hline Specialist visits & 5.8 & $\begin{array}{l}\text { Neumanm et al } \\
2015^{40}\end{array}$ & $\$ A 85.55$ & MBS 104 \\
\hline Serum urea & 16.7 & NICE HTA report ${ }^{41}$ & $\$ A 9.70$ & MBS 66500 \\
\hline Electrolytes test & 16.7 & NICE HTA report ${ }^{41}$ & $\$ A 9.70$ & MBS 66500 \\
\hline Creatinine test & 16.7 & NICE HTA report ${ }^{41}$ & $\$ A 9.70$ & MBS 66500 \\
\hline GFR§ & 16.7 & NICE HTA report ${ }^{41}$ & $\$ A 9.70$ & MBS 66500 \\
\hline \multicolumn{5}{|l|}{ Hospitalisation care } \\
\hline $\mathrm{HF}$ & Cost weight & & $\$ 9254.65$ & \\
\hline With severe complications & 2.39 & & $\$ 12423$ & AR-DRG F62A \\
\hline $\begin{array}{l}\text { Without severe } \\
\text { complications }\end{array}$ & 1.07 & & $\$ 5548$ & AR-DRG F62B \\
\hline Same-day admission & 0.58 & & $\$ 3037$ & AR-DRG F62C \\
\hline Death due to all causes & Per death & & $\$ 5199$ & Average cost across all AR-DRG items \\
\hline
\end{tabular}




\begin{tabular}{llll}
\hline & $\begin{array}{l}\% \text { of Patients } \\
\text { using this } \\
\text { resource } \quad \text { Source }\end{array} \quad$ Unit cost $\quad$ Sources of unit cost \\
\hline
\end{tabular}

*It was assumed that after catheter ablation procedure, patients do not need antiarrhythmic medications. The remaining medications are the same for both arms.

†According to the Australian Statistics on Medicines 2015, apixaban and atorvastatin+ezetimibe were the mostly prescribed agents. $\neq$ Calculated as the cost/average length of stay $=\$ A 3037 / 1.53$ for F62C (HF and shock, transfer less than 5 days).

$\S$ The estimated GFR is calculated by the pathology laboratory using the patient's age, sex and serum creatinine results. Generally calculated using CKD-EPI (Chronic Kidney Disease Epidemiology Collaboration) formula (https://www.rcpa.edu.au/Library/PractisingPathology/RCPA-Manual/Items/Pathology-Tests/E/eGFR).

ACE-I, ACE inhibitor; ARB, angiotensin II receptor blocker; AR-DRG, Australia Adjusted Disease Related Group; GFR, glomerular filtration rate; GP, general practitioner;HF, heart failure; MBS, medical benefits scheme;NICE, National Institute for Health and Care Excellence; PBS, pharmaceutical benefits scheme.

\section{RESULTS}

\section{Cost utility analysis}

Catheter ablation was associated with higher costs and benefits (ie, QALYs and LYs) over the lifetime of the cohort compared with medical therapy alone. The total cost was \$A44 377 per catheter ablation patient and \$A28 506 for the medically treated patient, representing an incremental difference of $\$ A 15871$. The primary cost components in both treatment groups were hospitalisation (\$A6564 in the catheter ablation vs $\$$ A5724 in the medical therapy) and medications (\$A14 656 in the catheter ablation vs \$A14 534 in the medical therapy) followed by the outpatient consultations ( $\$$ A3783 in the catheter ablation vs $\$$ A3539 in the medical therapy). The costs of AEs associated with the catheter ablation procedure were $\$ A 636$ and \$A14 063 for the initial and a repeat (\$A2977) of the procedure.

The corresponding QALYs and LYs were 4.58 and 6.99 in the catheter ablation arm, and 4.30 and 6.53 in the

Table 2 Cost of treating catheter ablation-related adverse events

\begin{tabular}{|c|c|c|c|}
\hline Adverse events & Unit cost & Sources & $\begin{array}{l}\text { Proportion } \\
\text { (\%) }\end{array}$ \\
\hline Pericardial effusion & $\begin{array}{l}\text { \$A11 } \\
601.00\end{array}$ & AR-DRG F61B & 1.68 \\
\hline Severe bleeding & $\$ A 9469.00$ & $\begin{array}{l}\text { AR-DRG } \\
\text { Q62A }\end{array}$ & 1.68 \\
\hline Minor bleeding & $\$ A 2476.00$ & $\begin{array}{l}\text { AR-DRG } \\
\text { Q62B }\end{array}$ & 1.12 \\
\hline $\begin{array}{l}\text { Pulmonary vein } \\
\text { stenosis }\end{array}$ & $\begin{array}{l}\$ A 11 \\
194.00\end{array}$ & AR-DRG F10B & 0.56 \\
\hline Pneumonia & $\$ A 5039.00$ & AR-DRG D63A & 1.68 \\
\hline Groin Infection & $\$ A 5039.00$ & AR-DRG D63A & 0.56 \\
\hline Fever & $\$ A 5039.00$ & AR-DRG D63A & 0.56 \\
\hline Worsen heart failure & $\$$ A9254.65 & $\begin{array}{l}\text { AR-DRG } \\
\text { F62A-C }\end{array}$ & 0.56 \\
\hline
\end{tabular}

The incidence of catheter ablation-related adverse events was sourced from the study by Marrouche et al $2018^{22}$, online supplementary table S11.

AR-DRG, Australian Refined Diagnosis Related Group. medical therapy arm, which resulted in ICERs of $\$ A 55$ 942/QALY and \$A35 020/LY, respectively (table 4). Based on the normally quoted WTP/QALY threshold in Australia, offering catheter ablation to patients with concomitant $\mathrm{AF}$ and $\mathrm{HF}$ who are not responsive to antiarrhythmic medications is not cost-effective.

\section{Sensitivity analyses}

The Tornado diagram shows that the ICER was mostly sensitive to the cost of ablation, time horizon and cost of outpatient care. The ICER was less sensitive to the probability of having repeated ablation, baseline utility, discount rate and cost of death. On contrary, ICER was not sensitive to the cost of hospitalisation due to worsening of HF. With the variation of these model parameters, the ICER varied to a certain extent (figure 2).

The PSA analyses by incorporating distribution of key model parameters showed that the mean results based on 5000 simulations of the probabilistic model were identical to the base case results (table 3 ). The probability of catheter ablation being not cost-effective was $84 \%$ based on the PSA analysis (figure 3). The cost-effectiveness acceptability curve showed that if the WTP/QALY threshold was greater than $\$ A 65000$, catheter ablation may become a cost-effective treatment strategy in comparison to medical treatment alone, with a probability of $92.7 \%$ (figure 4 ).

\section{DISCUSSION}

The inconsistency in the effectiveness of anti-AF treatment in the patients with concomitant HF or vice versa is well recognised. For example, beta blockers are indicated in patients with symptomatic HF with reduced ejection fraction while their poorer efficacy in patients with concomitant $\mathrm{HF}$ and $\mathrm{AF}$ precluded them being used preferentially over other rate-control medications and not regarded as standard therapy to improve patients' prognosis. ${ }^{15}$ Similarly, it was observed that adding antiarrythymic drugs for patients with severe HF led to increased early mortality related to the worsening of $\mathrm{HF}^{16}{ }^{1}$ It was recognised that incident $\mathrm{AF}$ has a profoundly negative effect on mortality and hospitalisations for $\mathrm{HF}$ with reduced ejection fraction, and it would certainly appear that the optional time for intervention in patients 
Table 3 Variables tested and the results from probabilistic sensitivity analyses

\begin{tabular}{|c|c|c|c|}
\hline Variable & \multicolumn{2}{|l|}{ Distribution } & Reference \\
\hline $\begin{array}{l}\text { Cost of hospitalisation due to worsening } \\
\text { of HF }\end{array}$ & \multicolumn{2}{|c|}{ Gamma (alpha 100, lambda 0.0108) } & Assumption \\
\hline $\begin{array}{l}\text { Disutility of a hospitalisation due to } \\
\text { worsening of HF }\end{array}$ & \multicolumn{2}{|l|}{ Beta (alpha 89.9, beta 809.1) } & Yao et $a l^{42}$ \\
\hline Utility of being in HF & \multicolumn{2}{|c|}{ Beta (alpha 657.72 , beta 323.95) } & Miller et al ${ }^{43}$ \\
\hline Cost & \$A44 378 (42 628, 46 193) & \$A28 $521(27$ 434, 29 705) & - \\
\hline QALYs & $4.57(3.63,5.43)$ & $4.28(3.39,5.09)$ & \$A55 234 \\
\hline
\end{tabular}

HF, heart failure; ICER, incremental cost-effectiveness ratio; LYs, life years; QALYs, quality-adjusted life years.

with HF is early after AF onset. ${ }^{29}$ This triggered exploration of the effectiveness of catheter ablation in patients with both $\mathrm{AF}$ and $\mathrm{HF}$ given its proven effectiveness in patients with AF. This answered an important clinical question as to whether to offer this expensive and invasive procedure to patients deemed at risk of high morbidity and mortality. The current study however, addressed another unanswered question in regard to the long-term cost-effectiveness of catheter ablation for patients comorbid with $\mathrm{AF}$ and $\mathrm{HF}$. It was found that catheter ablation was associated with higher cost and benefits (ie, QALYs and LYs gained), and the resultant ICER was \$A55 942/QALY, which is considered not cost-effective in the Australia healthcare setting.

Table 4 Base case results from the Markov model

\begin{tabular}{|c|c|c|c|}
\hline & $\begin{array}{l}\text { Catheter } \\
\text { ablation }\end{array}$ & $\begin{array}{l}\text { Medical } \\
\text { therapy }\end{array}$ & ICER \\
\hline Total cost & \$A4 377 & $\$ A 28506$ & - \\
\hline Medication & $\$ A 14656$ & \$A14 534 & - \\
\hline $\begin{array}{l}\text { Hospitalisation due } \\
\text { to HF }\end{array}$ & \$A6564 & \$A5724 & - \\
\hline $\mathrm{CA}$ and repeated $\mathrm{CA}^{*}$ & $\$ A 14063$ & 0 & - \\
\hline Examinations & $\$ A 541$ & $\$ A 506$ & - \\
\hline $\begin{array}{l}\text { Outpatient } \\
\text { consultation }\end{array}$ & \$A3783 & \$A3539 & - \\
\hline SAEs & \$A636 & 0 & - \\
\hline All cause deaths & $\$ A 4135$ & \$A4204 & - \\
\hline Number of death $\dagger$ & 9991 & 9992 & - \\
\hline $\begin{array}{l}\text { Number of } \\
\text { hospitalisation } \dagger\end{array}$ & 8052 & 7068 & - \\
\hline QALYs & 4.581 & 4.297 & $\begin{array}{l}\text { \$A55 942/ } \\
\text { QALY }\end{array}$ \\
\hline LYs & 6.985 & 6.532 & \$A35 020/LY \\
\hline
\end{tabular}

*The cost associated with SAEs due to the repeated CA was included.

†This is based on 10000 patients.

$\mathrm{CA}$, catheter ablation; HF, heart failure; ICER, incremental costeffectiveness ratio; LYs, life years; QALYs, quality-adjusted life years; SAEs, serious adverse events.
$\mathrm{AF}$ is one of the most common sustained arrhythmias in chronic HF. The prognostic influence of the presence of AF in $\mathrm{HF}$ is recognised, with studies reporting an independent adverse effect on mortality. AF is correlated with left ventricular (LV) systolic function and is associated with an adverse prognosis in HF regardless of the LV systolic function. ${ }^{14}$ Hence, treating the AF condition for patients with $\mathrm{HF}$ is of significant importance to improve their long-term survival.

$\mathrm{HF}$ is associated with high reoccurring readmission rates within 30 days of discharge, and a high number of deaths, nearly half of whom will die within 1 year of discharge. It was reported that $70 \%$ of $\mathrm{HF}$ healthcare costs are attributable to acute hospital care with more than 41000 people hospitalised annually in Australia (total number of hospitalisations due to circulatory conditions in Australia's hospitals was 556638 in 2015-16). ${ }^{30}$ The pressure to avoid or reduce hospitalisations for patients with HF is increasing particularly given the Federal government plans to penalise hospitals for exceeding the benchmark for readmission rates. From the pivotal trial, ${ }^{22}$ it was observed that hospitalisations due to the worsening of $\mathrm{HF}$ were reduced because of the treatment of patients with catheter ablation, which translates into cost savings in the long term. This is important and has policy implications to both the healthcare provider and the Federal government. It was worth noting that the benefits in relation

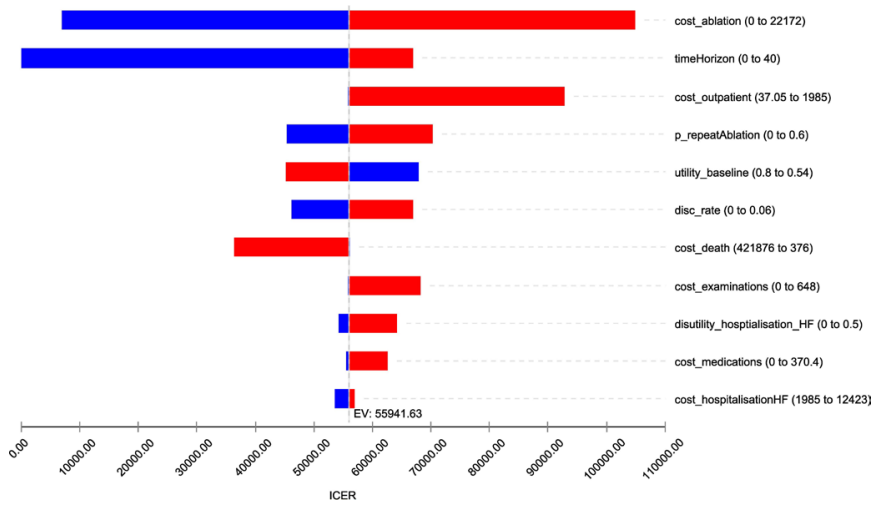

Figure 2 Results from the one-way deterministic sensitivity analysis_tornado diagram. 


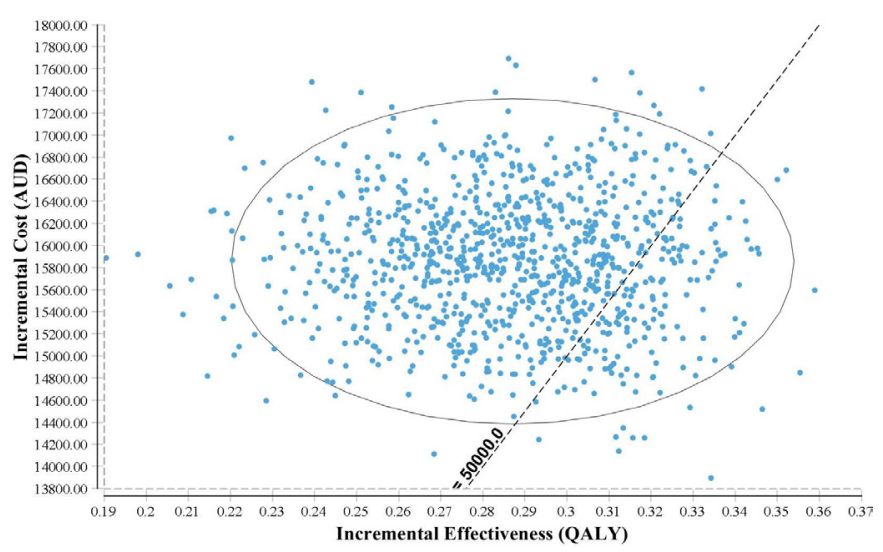

Figure 3 Cost-effectiveness plane. AUD, Asutralian dollar; QALY, quality-adjusted life years.

to the treatment of catheter ablation primarily lied with the reduced mortality due to the delayed worsening of heart function. For example, our model showed that per 10000 patients treated, the number of deaths over the lifetime horizon was 9991 in the catheter ablation arm versus 9992 in the medical therapy arm or a saving of 1 death. In contrast, the total number of hospitalisations over the lifetime of the cohort for worsening of HF per 10000 patients was 8052 in the catheter ablation group versus 7068 in the medical treatment group (while the maximum number of hospitalisations per person was seven in both groups). The higher number of hospitalisations in the catheter ablation group was due to the prolonged overall survival of patients (ie, the difference in LY was 0.453).

The cost-effectiveness of catheter ablation in the treatment of patients with AF has been well studied. In a study by Chan et al, comparing to medical therapy, catheter ablation had ICERs ranging from US\$28 700/QALY to US\$51 800/QALY depending on patient characteristics. ${ }^{31}$ A white paper by the Institute of Clinical and Economic Review examined the cost-effectiveness of AF rhythm control strategies in multiple contexts. Catheter ablation was investigated as first-line and second-line treatments compared with

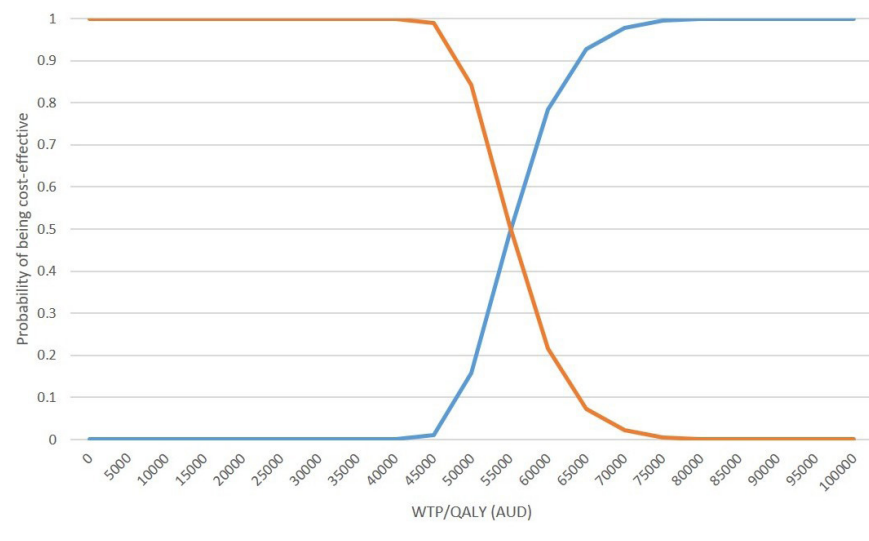

Figure 4 Cost-effectiveness acceptability curve. AUD, Australian dollar; QALY, quality-adjusted life year; WTP, willingness to pay. rate control as a second-line treatment following failure of amiodarone. The resultant ICERs varied from US\$26 869/ QALY (younger patients with low risk) to US\$80 615/QALY (older patients with high risk) for catheter ablation use as first line; while the ICERs were between US\$37 808/QALY (younger patients with low risk) and US\$96 846/QALY (older patients with high risk) when catheter ablation was modelled as a second-line therapy. ${ }^{32}$ A more recent study by Aronsson et al reported a baseline ICER of $€ 50570 /$ QALY when comparing catheter ablation with amiodarone as a first-line therapy for a lifetime horizon in four European countries. The ICER was lowest in younger patients ( $€ 3434 /$ QALY for those $\leq 50$ years vs $€ 108937 /$ QALY for those $>50$ years). ${ }^{33}$ Our study was the first to evaluate the cost-effectiveness of catheter ablation in patients with concomitant AF and HF. Since the underlying mortality and morbidity rates are significantly different in patients with $\mathrm{AF}$ alone and $\mathrm{AF}$ and HF concomitantly, ${ }^{34}$ the results are deemed not directly comparable. However, the total QALY gains for patients with HF predicted by other economic modelling studies were between 3.99 and $7.74^{36-38}$ over a lifetime horizon, while the results from the current study fell well within the range.

The greatest strength of the current study is that the most recent trial data were used to inform the model parameters. The widely used algorithm was employed to reconstruct the IPD from the published Kaplan-Meier curve. The transition probabilities from alive to death and experiencing hospitalisation (due to worsening of HF) were directly derived from the reconstructed IPD. In addition, extensive sensitivity analyses were conducted to examine the robustness of the base case results. As normal, this study comes with some limitations. The reconstructed IPD is only a maximum approximation of the real data. In particular, the model did not account for the repeated catheter ablation. However, the cost related to the repeated procedure was included, and it is believed that the reduced benefit attributable to the recurrent AF after the catheter ablation was captured in the pivotal trial, since the median follow-up was 37.8 months over the study. There are uncertainties around the extrapolation of Kaplan-Meier curves observed during the trial to the long term; however, the predicted QALY gains are very similar to the existing modelled studies in HF. Further, the ICER produced in the current study may be subject to changes given there are several ongoing trails examining the catheter ablation in the same patient population (RAFT-AF NCT01420393, EAST-AFNET4 NCT01288352, CABANA NCT00911508). Lastly, since the pivotal trial informed the efficacy of catheter ablation was conducted between 2008 and 2016, before the advent of state-of-art HF medical therapy (ie, sacubitril/valsartan), the incremental benefit from the catheter ablation might be overestimated to some extent, which would alter the cost-effectiveness conclusion. But the presented study could still provide important evidence for its interim cost-effectiveness. 


\section{CONCLUSIONS}

Offering catheter ablation procedure to patients with systematic paroxysmal or persistent $\mathrm{AF}$ who failed to respond to antiarrthythmic drugs was associated with higher costs and greater benefits in terms of QALYs and LYs gained in comparison to medical therapy alone. However, this intervention is not cost-effective from the Australia healthcare system perspective over a lifetime horizon given its likely shorter duration of effectiveness.

Acknowledgements LG is supported by the Alfred Deakin Postdoctoral Research Fellowship, Deakin University, Australia.

Contributors GL conceived and designed the study and drafted the manuscript. MM interpreted the results and critically revised the manuscript.

Funding The authors have not declared a specific grant for this research from any funding agency in the public, commercial or not-for-profit sectors.

Competing interests None declared.

Patient consent for publication Not required.

Provenance and peer review Not commissioned; externally peer reviewed.

Data availability statement All data relevant to the study are included in the article or uploaded as supplementary information.

Open access This is an open access article distributed in accordance with the Creative Commons Attribution Non Commercial (CC BY-NC 4.0) license, which permits others to distribute, remix, adapt, build upon this work non-commercially, and license their derivative works on different terms, provided the original work is properly cited, appropriate credit is given, any changes made indicated, and the use is non-commercial. See: http://creativecommons.org/licenses/by-nc/4.0/.

\section{REFERENCES}

1. Braunschweig F, Cowie MR, Auricchio A. What are the costs of heart failure? Europace 2011;13(suppl 2):ii13-17.

2. Guha K, McDonagh T. Heart failure epidemiology: European perspective. Curr Cardiol Rev 2013;9:123-7.

3. Wodchis WP, Bhatia RS, Leblanc K, et al. A review of the cost of atrial fibrillation. Value in Health 2012;15:240-8.

4. Chugh SS, Havmoeller R, Narayanan K, et al. Worldwide epidemiology of atrial fibrillation: a global burden of disease 2010 study. Circulation 2014;129:837-47.

5. Colilla S, Crow A, Petkun W, et al. Estimates of current and future incidence and prevalence of atrial fibrillation in the U.S. adult population. Am J Cardiol 2013;112:1142-7.

6. Australian Institute of Health and Welfare. Australia's health series no. 12. Cat. no. AUS 122. Canbarra: AlHW, 2010.

7. Desai AS, Stevenson LW. Rehospitalization for heart failure: predict or prevent? Circulation 2012;126:501-6.

8. Amin AN, Jhaveri M, Lin J. Hospital readmissions in US atrial fibrillation patients: occurrence and costs. Am J Ther 2013;20:143-50.

9. Chiang CE, Naditch-Brule L, Murin J, et al. Distribution and risk profile of paroxysmal, persistent, and permanent atrial fibrillation in routine clinical practice: insight from the real-life global survey evaluating patients with atrial fibrillation international registry. Circ Arrhythm Electrophysiol 2012;5:632-9.

10. van Deursen VM, Urso R, Laroche $\mathrm{C}$, et al. Co-Morbidities in patients with heart failure: an analysis of the European heart failure pilot survey. Eur J Heart Fail 2014;16:103-11.

11. Stewart S, Hart CL, Hole DJ, et al. A population-based study of the long-term risks associated with atrial fibrillation: 20-year follow-up of the Renfrew/Paisley study. Am J Med 2002;113:359-64.

12. Maisel WH, Stevenson LW. Atrial fibrillation in heart failure: epidemiology, pathophysiology, and rationale for therapy. Am J Cardiol 2003;91:2-8.

13. Wang TJ, Larson MG, Levy D, et al. Temporal relations of atrial fibrillation and congestive heart failure and their joint influence on mortality. Circulation 2003;107:2920-5.

14. Mamas MA, Caldwell JC, Chacko S, et al. A meta-analysis of the prognostic significance of atrial fibrillation in chronic heart failure. Eur $J$ Heart Fail 2009;11:676-83.

15. Kotecha D, Holmes J, Krum H, et al. Efficacy of $\beta$ blockers in patients with heart failure plus atrial fibrillation: an individual-patient data meta-analysis. Lancet 2014;384:2235-43.
16. Køber L, Torp-Pedersen C, McMurray JJV, et al. Increased mortality after dronedarone therapy for severe heart failure. N Engl J Med 2008;358:2678-87.

17. Wazni OM, Marrouche NF, Martin DO, et al. Radiofrequency ablation vs antiarrhythmic drugs as first-line treatment of symptomatic atrial fibrillation. JAMA 2005;293:2634-40.

18. Morillo CA, Verma A, Connolly SJ, et al. Radiofrequency ablation vs antiarrhythmic drugs as first-line treatment of paroxysmal atrial fibrillation (RAAFT-2). JAMA 2014;311:692-9.

19. Nielsen JC, Mortensen LS, Hansen PS. Radiofrequency ablation as initial therapy in paroxysmal atrial fibrillation. New Engl $\mathrm{J}$ Med 2013;368:478-9.

20. January CT, Wann LS, Alpert JS, et al. 2014 AHA/ACC/HRS guideline for the management of patients with atrial fibrillation: a report of the American College of Cardiology/American heart association Task force on practice guidelines and the heart rhythm Society. Circulation 2014;130:e199-267.

21. Fuster V, Rydén LE, Cannom DS, et al. ACC/AHA/ESC 2006 guidelines for the management of patients with atrial fibrillationexecutive summary: a report of the American College of Cardiology/ American heart association Task force on practice guidelines and the European Society of cardiology Committee for practice guidelines (writing Committee to revise the 2001 guidelines for the management of patients with atrial fibrillation). Eur Heart $J$ 2006;27:1979-2030.

22. Marrouche NF, Brachmann J, Andresen D, et al. Catheter ablation for atrial fibrillation with heart failure. N Engl J Med 2018;378:417-27.

23. Guyot P, Ades AE, Ouwens MJNM, et al. Enhanced secondary analysis of survival data: reconstructing the data from published Kaplan-Meier survival curves. BMC Med Res Methodol 2012;12:9.

24. Latimer NR. Survival analysis for economic evaluations alongside clinical trials--extrapolation with patient-level data: inconsistencies, limitations, and a practical guide. Med Decis Making 2013;33:743-54.

25. Royston P, Parmar MKB. Flexible parametric proportional-hazards and proportional-odds models for censored survival data, with application to prognostic modelling and estimation of treatment effects. Stat Med 2002;21:2175-97.

26. Pharmaceutical Benefits Advisory Committee. Guidelines for preparing submissions to the pharmaceutical benefits Advisory Committee (PBAC). version 5.0, 2016. Available: https://pbac.pbs. gov.au/ [Accessed 21 May 2018].

27. Ganesan AN, Shipp NJ, Brooks AG, et al. Long-term outcomes of catheter ablation of atrial fibrillation: a systematic review and Metaanalysis. J Am Heart Assoc 2013;2:e004549.

28. Wang S, Gum D, Merlin T. Comparing the ICERs in medicine reimbursement submissions to NICE and PBAC-Does the presence of an explicit threshold affect the ICER proposed? Value in Health 2018.

29. Verma A, Kalman JM, Callans DJ. Treatment of patients with atrial fibrillation and heart failure with reduced ejection fraction. Circulation 2017:135:1547-63.

30. Australian Institute of Health and Welfare. Admitted patient care 2015-16: Australian hospital statistics. health services series no. 75. cat. No. HSE 185. Canberra: AlHW, 2017.

31. Chan PS, Vijan S, Morady F, et al. Cost-Effectiveness of radiofrequency catheter ablation for atrial fibrillation. J Am Coll Cardiol 2006;47:2513-20.

32. Ollendorf DA, Silverstein MD, Bobo T. Management options for atrial fibrillation. US Institute for Clinical and Economic Review, 2010.

33. Aronsson $\mathrm{M}$, Walfridsson $\mathrm{H}$, Janzon $\mathrm{M}$, et al. The cost-effectiveness of radiofrequency catheter ablation as first-line treatment for paroxysmal atrial fibrillation: results from a MANTRA-PAF substudy. Europace 2015;17:48-55.

34. Chamberlain AM, Redfield MM, Alonso A, et al. Atrial fibrillation and mortality in heart failure: a community study. Circ Heart Fail 2011;4:740-6.

35. Santhanakrishnan R, Wang N, Larson MG, et al. Atrial fibrillation begets heart failure and vice versa: temporal associations and differences in preserved versus reduced ejection fraction. Circulation 2016;133:484-92.

36. Lee D, Wilson K, Akehurst R, et al. Cost-Effectiveness of eplerenone in patients with systolic heart failure and mild symptoms. Heart 2014;100:1681-7.

37. Almenar L, Díaz B, Quesada A, et al. Cost-Effectiveness analysis of cardiac resynchronization therapy in patients with NYHA I and NYHA II heart failure in Spain. Int $J$ Technol Assess Health Care 2013;29:140-6.

38. Griffiths A, Paracha N, Davies A, et al. The cost effectiveness of ivabradine in the treatment of chronic heart failure from the UK National health service perspective. Heart 2014;100:1031-6. 
39. Roy D, Talajic M, Nattel S, et al. Rhythm control versus rate control for atrial fibrillation and heart failure. N Engl $\mathrm{J} \mathrm{Med}$ 2008;358:2667-77.

40. Neumann A, Mostardt S, Biermann J, et al. Cost-Effectiveness and cost-utility of a structured collaborative disease management in the interdisciplinary network for heart failure (INH) study. Clin Res Cardiol 2015;104:304-9.

41. Pandor A, Thokala P, Gomersall T, et al. Home telemonitoring or structured telephone support programmes after recent discharge in patients with heart failure: systematic review and economic evaluation. Health Technol Assess 2013;17:1-208.

42. Yao G, Freemantle N, Flather M, et al. Long-Term cost-effectiveness analysis of nebivolol compared with standard care in elderly patients with heart failure: an individual patient-based simulation model. Pharmacoeconomics 2008;26:879-89.

43. Miller LC, Cox KR. Case management for patients with heart fialure: a quality improvement intervention. $J$ Gerontol Nurs $2005 ; 31: 20-8$ 